\title{
Por qué Baudelaire sigue cautivando ${ }^{1}$
}

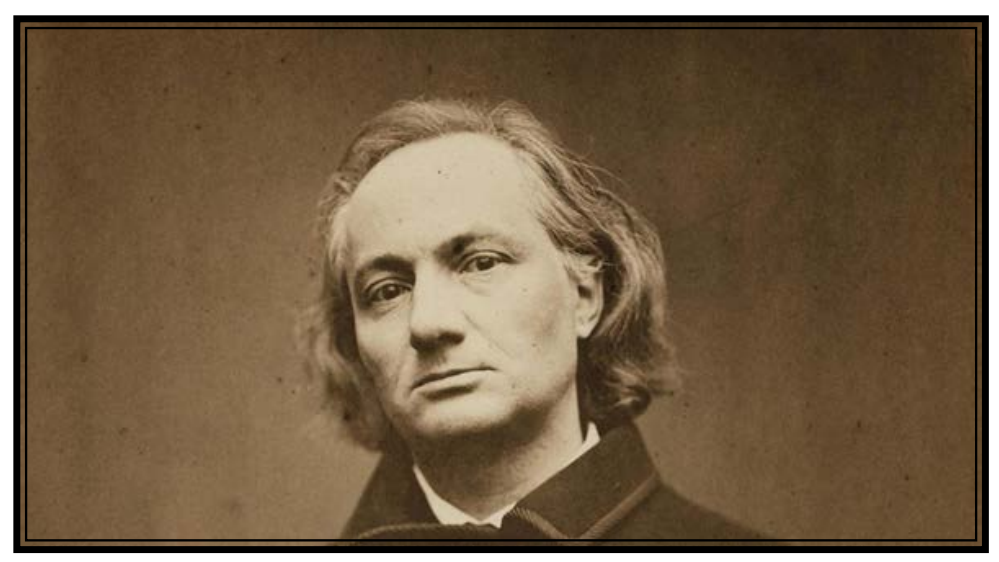

Con ocasión del aniversario 150 de la muerte de Baudelaire, André Guyaux, historiador de la literatura de la Sorbona, explica que el poeta es más que nunca un autor vigente.

Su nombre es conocido por todos, pero ¿cómo resumir en una palabra lo que fue Charles Baudelaire?

André Guyaux [1]: No se puede resumir en una palabra, pero debemos recordar que él es la gran figura del segundo periodo romántico. Nació en 1821, veinte años después de Víctor Hugo, y a lo largo de toda su obra, buscó su camino en lo que quedaba por explorar del romanticismo. Desde sus primeros trabajos, que no son poesía sino crítica de arte, se centra precisamente en definir el romanticismo. Él lo definió así: "Intimidad, espiritualidad, color, aspiración hacia lo infinito. Lo ve como "la expresión más contemporánea de la belleza" y no distingue entre el romanticismo y el arte moderno.

También explora los territorios del mal, aunque no le dieron una recepción muy favorable...

A.G.: Muy pronto, se le reconoce su importancia, pero sus obras son controvertidas y sus poemas son muy atacados. El juicio que valdrá para él, en 1857, la publicación de Las flores del mal no proviene de una irritación repentina de algunos magistrados, es el resultado de una campaña de prensa premeditada, que denuncia una obra "insalubre". Incluso si Baudelaire se convirtió rápidamente en una celebridad, todos los que se negaron a reconocer su genio lo consideraron peligroso. $\mathrm{Y}$ fueron algunos: Baudelaire no estaba del lado de la burguesía bien intencionada ni del lado de los progresistas.

Misántropo, dandy, drogadicto, cantor de la embriaguez ...: su época lo ve como el hombre del escándalo. ¿Todavía lo es hoy?

A.G.: Fueron sobre todo sus escritos libertinos, especialmente sus poemas lésbicos, los que provocaron el escándalo y el juicio. Los aspectos sulfurosos del personaje o los paraísos artificiales suscitaron menos preocupación. Sin embargo, debemos afirmar más que nunca su dimensión escandalosa: Baudelaire es el disidente absoluto. Sigue siendo la figura del poeta maldito, difícil de entender. Esto es lo que une a todos los que

1 Pourquoi Baudelaire fascine toujours, entrevista realizada por Francis Lecompte y publicada en el journal del CNRS, https://lejournal.cnrs.fr/articles/pourquoi-baudelaire-fascine-toujours [NdT] 
continúan investigando su trabajo: tratan de entender lo que está escribiendo. Mantuvo la contradicción, tenía un gusto por la paradoja, la línea sinuosa, y estamos buscando líneas rectas. Pero todos estamos fascinados por su profundidad.

De ahí el propósito del coloquio "El pensamiento de Baudelaire", celebrado en París a mediados de septiembre ${ }^{2}$, para el $150^{\circ}$ aniversario de su muerte.

A.G.: Sí, nos preguntamos si, detrás del poeta, podemos ver a un filósofo, si podemos encontrar en él la coherencia de un pensamiento. Esto es obviamente debate. Para algunos, el poeta es el hombre del dolor, de los sueños, de la contemplación, pero él no es un pensador. Para otros, él es un maestro del pensamiento. Él mismo nunca ha escrito textos filosóficos en sentido estricto, pero es autor de varios ensayos teóricos, incluido uno sobre comedia. Él apreció a los moralistas de los siglos XVII y XVIII, y él mismo practicó el aforismo fácilmente. Lo que se destaca, en cualquier caso, es un pensamiento de las ideologías del siglo XVIII y Joseph de Maistre, pero un poco convencional, esencialmente disidente.

Joseph de Maistre, que encarna la corriente contrarrevolucionaria en la década de 1790 ...

A.G.: Sí, Baudelaire lo llamó "clarividente" y dijo de él que con Edgar Poe le había "enseñado a razonar". Pero más allá o más allá de la fascinación que ejerce Joseph de Maistre sobre él, Baudelaire dirige la mayoría de sus críticas contra el progreso. Él es el anti-progresista por excelencia. Él nunca se cansa de mostrar el daño causado por la ilusión progresiva, lo que él llama la "religión" del progreso. Es cierto que, en el lapso de unas pocas décadas, llegaron las locomotoras y el alumbrado de gas, fue testigo del destripamiento de París cuando comenzó a perforar los grandes bulevares. Todo esto lo irritó y lo perturbó. Para la primera Feria Mundial en
París en 1855, Napoleón III quería máquinas en todas partes. Pero lo que Baudelaire no apoyó en absoluto es que el progresismo se aplique a la creación artística. Para él, la belleza no encuentra cronología: el artista es solitario, "singular"; él no tiene ascendencia o descendientes.

Era un hombre de su tiempo, Baudelaire sigue inspirando una gran cantidad de investigación. ¿Qué influencia ejerce todavía?

A.G.: Walter Benjamin, el filósofo e historiador de arte alemán del siglo XX, dijo que nada en el trabajo del poeta "ha envejecido". De hecho, su trabajo no envejece. Entonces siempre podemos referirnos a él para entender el mundo. Generaciones de escritores también lo han reclamado: Verlaine y Mallarmé, luego Valéry, Claudel y los surrealistas, hasta Yves Bonnefoy. Más cerca de nosotros, Michel Houellebecq es un gran lector de Baudelaire. En nuestro coloquio, tuvimos investigadores de todas las generaciones, pero también académicos de Italia, Alemania, Gran Bretaña, Estados Unidos... Baudelaire es estudiado en China, Japón y Brasil. Baudelaire, el poeta parisino por excelencia, tiene una audiencia mundial. Solo existe la ciudad de París y sus servicios culturales que aún no le han dado la medida.

\section{¿Podemos decir que su influencia va más allá del simple círculo de la literatura?}

A.G.: Baudelaire siempre ha girado en torno a la idea de la modernidad. Fue él quien dio el significado a esta palabra. Murió demasiado temprano para ver el nacimiento de la escuela impresionista, pero frente a las acuarelas de Constantin Guys, tiene esta fórmula: "La modernidad es lo transitorio, lo fugitivo, lo contingente, la mitad del arte, de los cuales la otra mitad es lo eterno e inmutable. El concepto no es fácil de explicar. Para él, la modernidad es el contrapunto positivo del progreso: si el arte es eterno, también se alimenta de todo lo nuevo, como la fotografía, que Baudelaire vio nacer. La

2 Coloquio La Pensée de Baudelaire realizado en Paris los días 11, 12 y13 de septiembre de 2017 organizado por André Guyaux, Bertrand Marchal y Eve Morisi. [NdT] 
modernidad es todos estos elementos fugitivos que el arte puede capturar.

\section{Pero también es complejo, ¿tan difícil de acceder?}

A.G.: Baudelaire habla a lectores de todos los ámbitos de la vida, a veces muy alejados del mundo de la literatura. A los catorce años, uno puedeleer El Albatros y vibrar a sus "alas gigantes" que "le impiden caminar". Lo mismo ocurre con sus poemas sobre las multitudes o sobre las transformaciones de las grandes metrópolis, uno de los fenómenos de su tiempo que pudo tocar concretamente. Da un motivo de reflexión a todos los interesados en sociología. Estos textos ofrecen una imagen social sorprendente, a pesar de sus ambivalencias. Pienso, por ejemplo, en las Petites Vieilles: navegamos entre la caridad y la crueldad en Baudelaire, siempre estamos en lo indecidible.

¿Sigue siendo la imagen de un hombre que se inclina hacia la oscuridad, que no está realmente en el tono de hoy?

A.G.: en Le Voyage (en la segunda edición de Lesfleurs du mal), los viajeros viajan por el mundo para cambiar su clima. Pero en cada etapa, solo descubren "el aburrido espectáculo del pecado inmortal". Baudelaire odiaba el optimismo, eso es lo que lo mantuvo en movimiento. Él es un centinela contra la tentación de la ingenuidad que nos amenaza. De paso, debe enfatizarse que también podría estar en el corazón de los debates teológicos. Él creía en el pecado original. Estaba convencido de que había un origen del mal y que el hombre estaba marcado para siempre. El título Les fleurs du mal proviene de esta convicción y Baudelaire quería que el frontispicio de su libro se inspirara en una imagen de la Caída de Adán y Eva.

http://plus.lesoir.be/126651/article/2017-11-29/unportrait-de-charles-baudelaire-vendu-112500-euros 